\title{
The COVID-19 pandemic: a new epoch and fresh challenges for cancer patients and caregivers - a descriptive cross-sectional study
}

\author{
Seema Mishra ${ }^{1}$ - Raghav Gupta $^{1} \cdot$ Sushma Bhatnagar ${ }^{1} \cdot$ Rakesh Garg $^{1} \cdot$ Sachidanand Jee Bharati ${ }^{1} \cdot$ Vinod Kumar $^{1}$. \\ Nishkarsh Gupta ${ }^{1}$
}

Received: 30 April 2021 / Accepted: 9 September 2021 / Published online: 18 September 2021

(c) The Author(s), under exclusive licence to Springer-Verlag GmbH Germany, part of Springer Nature 2021

\begin{abstract}
Purpose Cancer patients and their caregivers are overwhelmed with features of uncertainty, fear, shock, worry, anxiety, sadness, and grief. To add on to their misery, the COVID-19 pandemic has severely afflicted the cancer care delivery. The study was conducted to observe the challenges faced by cancer patients and their caregivers and to formulate strategies for oncological setups to overcome those challenges.

Methods After obtaining institutional ethical clearance, a descriptive cross-sectional study was conducted to observe the challenges faced by patients and their caregivers at the level of various domains (physical, logistic, psychological, socioeconomic, and spiritual) who visited the outpatient and inpatient department of cancer pain and palliative care unit. The results were expressed in absolute numbers.

Results Major challenges encountered were suffering from physical symptoms like pain, nausea, vomiting, dyspnea (90\%), postponement of cancer treatment (80\%), fear of contracting COVID infection due to hospital visit (93.5\%), lack of accommodation (70\%), and lack of spiritual clarity and hope (50\%).

Conclusions Major challenges faced by patients were in physical and psychological domains, and those by caregivers were in socioeconomic domains and handling physical symptoms of their patients. It is imperative to recognize and be cognizant of the challenges faced by cancer patients and their caregivers. Health care setups should formulate strategies to alleviate these challenges and provide holistic care to cancer patients. These strategies will hold in good stead for future pandemics also.
\end{abstract}

Keywords Cancer patients $\cdot$ Caregivers $\cdot$ Challenges $\cdot$ COVID-19 pandemic $\cdot$ Strategies

\section{Introduction}

The Coronavirus disease 2019 also known as "COVID19 " which was first detected in China and later on declared a pandemic by WHO on March 12, 2020 [1], has created havoc all over the world in a very short span of time. It

Key message The study highlights the challenges faced by cancer patients and their caregivers during COVID 19 pandemic at the level of various domains-physical, logistic, psychological, socioeconomic and spiritual. Thus, it is imperative to recognize these challenges and frame strategies for providing holistic care for future pandemics as well.

Seema Mishra

seemamishra2003@gmail.com

1 Department of Onco-Anesthesia and Palliative Medicine, Dr B.R.A. Institute Rotary Cancer Hospital, AIIMS, New Delhi 110029, India has impacted every country on various fronts including economic, social, and political [2]. On the health front, the cancer patients and those with underlying comorbidities have an increased risk of admissions in intensive care units $[3,4]$. The estimated case fatality rate in cancer patients with COVID-19 is 6\%, [5] as compared to $1 \%$ among the general population [5,6]. There is a substantial number of cancer patients in whom treatment delay will affect the survival as well as quality of life. In India, the estimated number of cancer cases is approximately 2.25 million; therefore, the impact of this pandemic on cancer patients will be grave [7]. To curb the COVID-19 menace, countries and health care systems around the world have taken various measures like nationwide lockdown, strict social distancing protocols, and restriction of the healthcare facilities to patients and their caregivers through triaging. It has been advised to defer surgery, chemotherapy, and radiotherapy in patients with chances of marginal benefit. All these steps have helped 
in preventing the spread of the disease to a large extent, but at the same time, it has raised many hurdles and new challenges. With this background, we conducted a descriptive cross-sectional study on the challenges faced by cancer patients and their caregivers on various fronts-physical, logistic, psychological, socioeconomic, and spiritual.

\section{Materials and methods}

\section{Study design}

The descriptive cross-sectional study was conducted by the Department of Onco-Anesthesia and Palliative Medicine at Dr. BRA, IRCH, AIIMS, New Delhi. Permission was obtained from the Institute Ethics Committee of AIIMS Hospital, New Delhi, India (IEC-448/22/05.2020).

\section{Selection of the participants}

The cross-sectional study was conducted from June 1, 2020, to July 30, 2020, and included adult ( $>18$ years) out-patients and in-patients along with their caregivers attending the cancer pain and palliative care unit and willing to participate in the study. Those with an inability to understand Hindi/English and with features of influenza-like illness/severe acute respiratory illness like fever, cough sore throat, and myalgia were excluded.

\section{Aims and objectives}

The main aim was to assess the challenges and hardships faced by the cancer patients and their caregivers during the COVID-19 pandemic at the level of various domains (physical, logistic, psychological, socioeconomic, and spiritual). The secondary objective was to assess the maximum affected domain among patients and their caregivers.

\section{Methodology}

As there was no previous literature available regarding the challenges faced by cancer patients and caregivers during the COVID-19 pandemic, we designed our own questionnaire based upon the clinical experience of pain and palliative care physicians at our center. The convenience sampling approach was used to collect data. The adult patients and their caregivers who attended the pain and palliative care unit and were willing to participate in the study were included. Patients with features of influenza like illness or severe acute respiratory illness were advised to go to a COVID screening facility and were excluded from the study. To check the validity of the questionnaire, an information sheet was prepared in excel for an expert group to grade each question based on relevance, simplicity, clarity, and ambiguity of framed questions on a 4-point scale and was mailed to five experts. Content validity was estimated using the content validity index. All the five experts completed the evaluation and grading. Questions raised by them were sorted out, and an agreement was sought. After there was hundred percent agreement among all the experts, the questionnaire was finalized. Two columns were made in the questionnaire, one each for the patients' response and their caregivers' response. In the hospital setup, few patients came alone, few came with their caregivers, and in some cases only caregivers came. The team of pain and palliative care physicians asked the questions and noted down the basic demographic information (age/gender/address). Diagnosis, staging, ECOG (Eastern Cooperative Oncology Group) status of the patient, and treatment received/ongoing were also noted. Patients and their caregivers were asked questions by physicians and had to respond in binary response form (Yes/No) in various domains like physical, logistic, psychological, socioeconomic, and spiritual. If only the patient was present, response was noted in the patient column; if only the caregiver was present, response was noted down in the caregiver column; and if both were present, responses in both patient and caregiver columns were noted.

- Physical domain: one question was asked-whether patients were suffering from symptoms like pain, nausea, vomiting, constipation, diarrhea, and dyspnea.

- Logistic domain: four questions were asked-if was there any difficulty in commuting to the hospital, if there was any postponement of treatment and investigations, and whether they encountered restricted medical delivery.

- Psychological domain: six questions were asked-if there was any fear of progression of disease due to postponement of treatment and investigations, if there was any fear of contracting infection or transmission of infection to family members due to hospital visit, if they have any fear of inability to afford the treatment cost due to financial loss during lockdown, and if they feel any lack of emotional support.

- Socioeconomic domain: five questions were asked-if there were any financial loss, social outcast by society, lack of accommodation, lack of support system for daily needs, and difficulty in maintaining social distancing because of lack of proper space at home.

- Spiritual domain: three questions were asked-if there was any lack of spiritual and religious devotion, lack of spiritual clarity, and hope and feeling of fatalism.

Subsequently, three groups were formed for analysisone in which only the patient visited the hospital (group P), one in which only the caregiver came (group CG), and a third one in which both patient and caregiver were present 
(group $\mathrm{P}+\mathrm{CG}$ ). Groups were formed keeping in mind the hardship and challenges faced by caregivers also. Caregivers not only have to face the challenges themselves but also have to deal with the hardship faced by their patients.

\section{Statistical analysis}

In the absence of any previous study, the convenience sampling approach was used to collect data. Data were entered in Microsoft excel sheet and analyzed by Stata 14 software. For categorical data, standard descriptive statistics such as absolute numbers and percentages were used. For comparison between the three groups with each other and for inert group comparison, the chi-square test was used and a $\mathrm{P}$ value of $<0.05$ was considered to be statistically significant.

\section{Results}

A total of 515 individuals coming to the cancer center were screened. Fifteen individuals were excluded as they had features suggestive of influenza-like illness/severe acute respiratory illness. Out of the remaining 500 cases, in 310 (62\%) cases both patients and caregivers (group P+CG) were present. In 140 (28\%) cases only the patient was there (group P), and in $50(10 \%)$ cases only the caregiver came to the hospital (group CG). A total of 175 (35\%) patients had undergone some form of treatment, either chemotherapy, radiotherapy, or surgery; the remaining 325 (65\%) patients were under the category of ongoing treatment (Table 1).

At the level of the physical domain, in group $\mathrm{P}+\mathrm{CG}$, $279(90 \%)$ respondents mentioned that their symptoms like pain/nausea/vomiting/constipation/diarrhea or dyspnea got aggravated due to inability to procure medications (Fig. 1).
There was no statistical significance when three groups were compared with each other $(P$ value $=0.66)$.

At the level of logistic domain, 250 (80.6\%) respondents (group P + CG) mentioned that they had difficulty in procuring medications. When the three groups were compared with each other, there was statistical significance seen for postponement of surgery, chemotherapy, and radiotherapy (0.007), as well as for postponement of routine investigations like CBC (complete blood count), LFT (liver function test), KFT (kidney function test) and imaging like CT (computerized tomography), MRI (magnetic resonance imaging), and PET (positron emission tomography) scan leading to anxiety (0.008). Statistical significance was also noted for postponement of surgery/radiotherapy/chemotherapy when group $\mathrm{P}$ was compared with group CG $(\mathrm{P}$ value $=0.010)($ Table 2$)$.

At the level of the psychological domain, 290 (93.5\%) respondents (group $\mathrm{P}+\mathrm{CG}$ ) mentioned that they faced maximum challenge in fear of contracting COVID infection due to hospital visits. When the three groups were compared with each other, there was statistical significance seen in all the challenges (Table 3 ) faced at the level of the psychological domain $(P$ value $<0.05)$. When group $\mathrm{P}+\mathrm{CG}$ was compared with group $\mathrm{P}$, there was statistical significance for fear of transmitting infection to other family members ( $\mathrm{P}$ value $=0.006$ for adjusted $\mathrm{P}$ value $<0.016$, for multiple comparison testing). Also, when group $\mathrm{P}$ was compared with group $\mathrm{CG}$ there was statistical significance seen $(\mathrm{P}$ value $=0.006$ for adjusted $p$ value $<0.016$, for multiple-comparison testing) for fear of the progression of disease due to postponement of anticancer therapies, fear for postponement of imaging leading to anxiety of progression of newly diagnosed cancer, fear of contracting infection by hospital visit, and fear of inability to bear cost of treatment due to financial loss: more in patients compared to caregivers alone.
Fig. 1 Challenges faced at the level of the physical domain

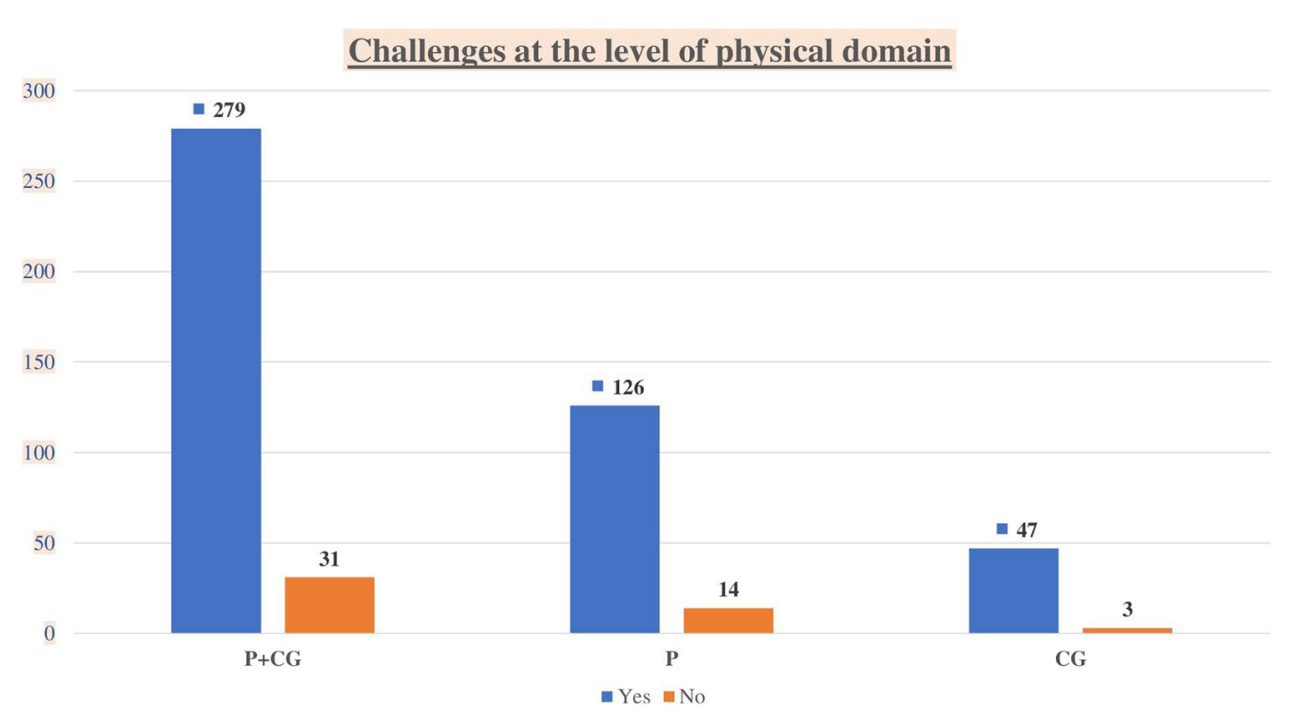


Table 1 Distribution of cancer diagnosis

\begin{tabular}{|c|c|}
\hline Demographic parameters & Number (\%) \\
\hline \multicolumn{2}{|l|}{ Patients } \\
\hline \multicolumn{2}{|l|}{ Types of cancer } \\
\hline Head and neck & $105(21)$ \\
\hline Breast & $100(20)$ \\
\hline Thoracic & $15(3)$ \\
\hline Gastrointestinal & $60(12)$ \\
\hline Endocrine & $25(5)$ \\
\hline Genitourinary & 95 (19) \\
\hline Musculoskeletal & $25(5)$ \\
\hline Neurological & $18(3.6)$ \\
\hline Skin & $12(2.4)$ \\
\hline Hematological & $45(9)$ \\
\hline \multicolumn{2}{|l|}{ Duration of diagnosis } \\
\hline$<1$ year/ $1-2$ years $/>2$ years & $225 / 215 / 60(45 / 43 / 12)$ \\
\hline \multicolumn{2}{|l|}{ Gender } \\
\hline Men/women & $270 / 230(54 / 46)$ \\
\hline \multicolumn{2}{|l|}{ Age range } \\
\hline $18-30 / 31-40 / 41-50 / 51-60 / 61-70$ & $70 / 100 / 130 / 120 / 80(14 / 20 / 26 / 24 / 16)$ \\
\hline \multicolumn{2}{|l|}{ Stage } \\
\hline I/II/III/IV & $100 / 200 / 130 / 70(20 / 40 / 26 / 14)$ \\
\hline \multicolumn{2}{|l|}{ ECOG status } \\
\hline $1 / 2 / 3 / 4$ & $90 / 300 / 60 / 50(18 / 60 / 12 / 10)$ \\
\hline \multicolumn{2}{|l|}{ Caregivers } \\
\hline Caregivers who came along with patient & $310(86.1)$ \\
\hline Caregivers who came alone & $50(13.9)$ \\
\hline \multicolumn{2}{|l|}{ Gender } \\
\hline Men/women & $300 / 60(83.3 / 16.7)$ \\
\hline \multicolumn{2}{|l|}{ Age range } \\
\hline $18-30 / 31-40 / 41-50 / 51-60 / 61-70$ & $80 / 140 / 100 / 30 / 10(22.2 / 38.8 / 27.7 / 8.3 / 2.7)$ \\
\hline
\end{tabular}

At the level of the socioeconomic domain, 217 (70\%) respondents (group $\mathrm{P}+\mathrm{CG}$ ) mentioned that they faced maximum challenge in the lack of accommodation. During comparison of three groups with each other, there was statistical significance $(\mathrm{P}$ value $<0.05)$ noted in lack of accommodation, difficulty in maintain social distancing because of lack of proper space at home, and financial loss because of lockdown (Table 4). When group $\mathrm{P}$ was compared with group CG, there was statistical significance $(P<0.016$, for multiple-comparison testing) for lack of accommodation: more in patients compared to caregivers alone.

At the level of the spiritual domain, 155 (50\%) respondents (group P $+\mathrm{CG}$ ) faced lack of spiritual clarity and hope. During the comparison of three groups with each other, there was statistical significance $(P$ value $<0.05)$ in lack of spiritual clarity and hope (Table 5). During comparison of group $\mathrm{P}+\mathrm{CG}$ with group $\mathrm{P}$, statistical significance was noted for feeling of fatalism $(P$ value $<0.0001$ for adjusted $\mathrm{P}$ value $<0.016$, for multiple-comparison testing). Also, when group $\mathrm{P}$ was compared with group $\mathrm{CG}$ there was statistical significance $(P<0.016$, for multiple-comparison testing) for lack of spiritual clarity and hope-more in patients compared to caregivers alone.

\section{Discussion}

Cancer patients face tremendous hardships on various fronts-be it physical, logistic, psychological, socioeconomic, or spiritual. In our study, challenges faced by cancer patients and their caregivers at the level of these various domains during the COVID-19 pandemic have been highlighted. Major challenges faced by patients were in physical and psychological domains, and those by caregivers were in the socioeconomic domain and handling physical symptoms of their patients. The COVID-19 pandemic exacerbated the old challenges (e.g., fear of progression of disease, fear of inability to afford cost of treatment, lack of emotional support, lack of spiritual clarity) and symptoms (e.g., physical symptoms like pain, nausea, constipation, dyspnea) which 
Table 2 Challenges faced at the level of the logistic domain

\begin{tabular}{|c|c|c|c|c|}
\hline Challenges & Groups & Yes & No & $P$ value \\
\hline \multirow[t]{3}{*}{ Difficulty in to and fro transportation to the hospital } & Group P+CG & $232(74.8 \%)$ & $78(25.2 \%)$ & \multirow[t]{3}{*}{0.497} \\
\hline & Group P & $98(70 \%)$ & $42(30 \%)$ & \\
\hline & Group CG & $35(70 \%)$ & $15(30 \%)$ & \\
\hline \multirow[t]{4}{*}{ Postponement of surgery/RT/CT } & Groups & Yes & No & \multirow[t]{4}{*}{$0.007 *$} \\
\hline & Group P+CG & $248(80 \%)$ & $62(20 \%)$ & \\
\hline & Group P & $110(78.6 \%)$ & $30(21.4 \%)$ & \\
\hline & Group CG & $30(60 \%)$ & $20(40 \%)$ & \\
\hline \multirow{4}{*}{$\begin{array}{l}\text { Postponement of routine investigations like } \mathrm{CBC}, \mathrm{LFT}, \mathrm{KFT} \text { and } \\
\text { imaging like CT, MRI, PET scan leads to anxiety }\end{array}$} & Groups & Yes & No & \multirow[t]{4}{*}{$0.008 *$} \\
\hline & Group $\mathrm{P}+\mathrm{CG}$ & $245(79 \%)$ & $65(21 \%)$ & \\
\hline & Group P & $100(71.4 \%)$ & $40(28.6 \%)$ & \\
\hline & Group CG & $30(60 \%)$ & $20(40 \%)$ & \\
\hline \multirow{4}{*}{$\begin{array}{l}\text { Restricted medical delivery system } \\
\text {-Routine OPD } \\
\text {-Indoor facility } \\
\text {-Difficulty in procuring medications } \\
\text {-Difficulty in procuring }\end{array}$} & Groups & Yes & No & \multirow[t]{4}{*}{0.985} \\
\hline & Group $\mathrm{P}+\mathrm{CG}$ & $250(80.6 \%)$ & $60(19.4 \%)$ & \\
\hline & Group P & $112(80 \%)$ & $28(20 \%)$ & \\
\hline & Group CG & $40(80 \%)$ & $10(20 \%)$ & \\
\hline
\end{tabular}

Group P + CG $(N=310)$ : patients who came along with their caregivers

Group $\mathrm{P}(N=140)$ : patients alone

Group CG $(N=50)$ : caregivers alone

For comparison between three groups with each other: chi-square test was used

$* P$ value of $<0.05$ was considered to be statistically significant

the patients and their caregivers were already facing. Also, it led to the situation where the patients and caregivers had to face new challenges (e.g., difficulty in commuting to the hospital during lockdown, postponement of surgeries and investigations, fear of contracting COVID infection by hospital visit, fear of transmitting infection to other family members, social outcast by the society, and lack of religious devotion).

To strike a balance between managing cancer and preventing the patients and caregivers from contracting COVID infection, hospitals have adopted various policies including triaging the patients, use of telemedicine facility, policies of hand hygiene, and social distancing. Countries worldwide enforced lockdown for months to prevent the spread of coronavirus infection. Studies conducted have suggested avoidance of complex surgeries which require multiple transfusions and prolonged intensive care unit stays [8,9]. Palliative radiotherapy in a single fraction has been recommended to reduce the hospital visits $[8,9]$. Systemic chemotherapy has also been suggested to be deferred especially in patients with chances of minimal benefit [10]. All this has aggravated the problems for cancer patients and their caregivers.

At the level of the physical domain, patients reported that they faced a lot of symptoms ranging from pain, nausea, vomiting, bowel disturbances, and dyspnea which have been aggravated due to inability to procure medications because of logistic issues like difficulty of transportation and restricted medical delivery system during lockdown. Symptomatic management is important for all cancer patients and even more so for patients who are in the advanced stage of their disease. A high proportion of patients complaining of inadequate symptom control highlight the poor quality of life. Inability to control the physical symptoms was a major challenge for the caregivers. They also felt helpless and did not know how to help their patients in such a situation.

At the level of the logistic domain, due to the nationwide policy of lockdown, patients and caregivers had trouble reaching the hospital due to non-availability of the public transport system. A major proportion of patients and caregivers reported that their routine blood investigations like complete blood count, kidney and liver function tests, and imaging modalities like PET scan, CT scan, and MRI were getting postponed. Also, their scheduled dates for surgery, chemotherapy, and radiotherapy got delayed. They found it difficult to procure their medications, and many felt that because of the restricted policy of seeing a limited number of patients they could not meet their physicians in person. Statistical significance was observed when group $\mathrm{P}$ was compared to group CG in terms of postponement of surgery/ radiotherapy/chemotherapy. This implies that the patients worried more regarding the progression of their disease, and thus this challenge must be duly addressed by healthcare system during pandemics.

The word cancer itself instills fear in the mind of people. On the top of it, patients now also have to cope up with the possibility of contracting coronavirus infection because of their debilitated immunity. At the level of the psychological 
Table 3 Challenges faced at the level of the psychological domain

\begin{tabular}{|c|c|c|c|c|}
\hline Challenges & Groups & Yes & No & $P$ value \\
\hline Fear of the progression of disease due to postponement of anticancer therapies & $\begin{array}{l}\text { Group P +CG } \\
\text { Group P } \\
\text { Group CG }\end{array}$ & $\begin{array}{l}279(90 \%) \\
126(90 \%) \\
35(70 \%)\end{array}$ & $\begin{array}{l}31(10 \%) \\
14(10 \%) \\
15(30 \%)\end{array}$ & $0.000 *$ \\
\hline $\begin{array}{l}\text { Postponement of imaging like CT, MRI and PET scan leads to anxiety of progres- } \\
\text { sion of newly diagnosed cancer }\end{array}$ & $\begin{array}{l}\text { Group P+CG } \\
\text { Group P } \\
\text { Group CG }\end{array}$ & $\begin{array}{l}\text { Yes } \\
270(87.1 \%) \\
120(85.7 \%) \\
32(64 \%)\end{array}$ & $\begin{array}{l}\text { No } \\
40(12.9 \%) \\
20(14.3 \%) \\
18(36 \%)\end{array}$ & $0.000 *$ \\
\hline Fear of contracting infection by hospital visit & $\begin{array}{l}\text { Group P + CG } \\
\text { Group P } \\
\text { Group CG }\end{array}$ & $\begin{array}{l}\text { Yes } \\
290(93.5 \%) \\
130(92.8 \%) \\
40(80 \%)\end{array}$ & $\begin{array}{l}\text { No } \\
20(6.5 \%) \\
10(7.2 \%) \\
10(20 \%)\end{array}$ & $0.004 *$ \\
\hline Fear of transmitting infection to other family members & $\begin{array}{l}\text { Group P+CG } \\
\text { Group P } \\
\text { Group CG }\end{array}$ & $\begin{array}{l}\text { Yes } \\
280(90.3 \%) \\
110(78.5 \%) \\
40(80 \%)\end{array}$ & $\begin{array}{l}\text { No } \\
30(9.7 \%) \\
30(21.5 \%) \\
10(20 \%)\end{array}$ & $0.002 *$ \\
\hline Fear of inability to afford cost of treatment because of financial loss & $\begin{array}{l}\text { Group P+CG } \\
\text { Group P } \\
\text { Group CG }\end{array}$ & $\begin{array}{l}\text { Yes } \\
260(83.9 \%) \\
120(85.7 \%) \\
35(70 \%)\end{array}$ & $\begin{array}{l}\text { No } \\
50(16.1 \%) \\
20(14.3 \%) \\
15(30 \%)\end{array}$ & $\mathbf{0 . 0 3} *$ \\
\hline Lack of emotional support & $\begin{array}{l}\text { Group P+CG } \\
\text { Group P } \\
\text { Group CG }\end{array}$ & $\begin{array}{l}\text { Yes } \\
250(80.6 \%) \\
100(71.4 \%) \\
30(60 \%)\end{array}$ & $\begin{array}{l}\text { No } \\
60(19.4 \%) \\
40(28.6 \%) \\
20(40 \%)\end{array}$ & 0.002* \\
\hline
\end{tabular}

Group $\mathrm{P}+\mathrm{CG}(N=310)$ : patients who came along with their caregivers

Group $\mathrm{P}(N=140)$ : patients alone

Group CG $(N=50)$ : caregivers alone

For comparison between three groups with each other, chi square test was used

$* P$ value of $<0.05$ was considered to be statistically significant

domain, majority of patients and their caregivers reported fear regarding the progression of their disease due to postponement of their treatment and scheduled imaging. Patients were worried that they may contract the COVID infection because of the immunocompromised state by their frequent hospital visits, and caregivers were stressed out thinking that they may carry the infection back home if they visit the hospital $[11,12]$. When group P was individually compared with group $\mathrm{CG}$, fear of postponement of treatment and contracting infection was more. This implies that patients had more psychological challenges when compared to their caregivers. Also, fear of transmitting infection was statistically significant in the group of patients alone versus when patients had the support of caregivers with them. This implies that the patients who had support of their caregivers were better equipped to deal with their psychological challenges. Literature also supports the fact that cancer patients who have a constant support of their family members and friends return to their coping strategies within 1-2 weeks [13]. Support of caregivers helps in better psychological adjustment compared to patients who are all alone [14]. Bonding of patients with the community, family members, and their own spiritual or religious belief system is important for healing and important component of overall cancer treatment [15].

It was also reported that due to loss of jobs during lockdown they incurred huge financial loss and may not be able to bear the cost of the whole cancer treatment process. Even though the policy of lockdown helped curb the spread of infection, at the same time it has caused huge economical loss to the countries. It becomes even more difficult for the developing countries like India. At the level of the socioeconomic domain, patients reported that they faced issues like lack of accommodation more in comparison to their caregivers. Caregivers faced major challenges in this domain-like difficulty in maintaining social distancing because of lack of proper space at home, encountered social outcast by the society stating that they have a cancer patient at home, and also incurred huge financial loss affecting the treatment of their patient. In literature, also it has been observed that 
Table 4 Challenges faced at the level of the socioeconomic domain

\begin{tabular}{|c|c|c|c|c|}
\hline Challenges & Groups & Yes & No & $\mathrm{P}$ value \\
\hline \multirow[t]{3}{*}{ Lack of accommodation } & Group P + CG & $217(70 \%)$ & $93(30 \%)$ & \multirow[t]{3}{*}{$\mathbf{0 . 0 3 *}$} \\
\hline & Group P & $110(78.5 \%)$ & $30(21.5 \%)$ & \\
\hline & Group CG & $30(60 \%)$ & $20(40 \%)$ & \\
\hline \multirow[t]{4}{*}{ Difficulty in maintain social distancing because of lack of proper space at home } & & Yes & No & \multirow[t]{4}{*}{$0.006 *$} \\
\hline & Group $\mathrm{P}+\mathrm{CG}$ & $124(40 \%)$ & $186(60 \%)$ & \\
\hline & Group P & $70(50 \%)$ & $70(50 \%)$ & \\
\hline & Group CG & $20(40 \%)$ & $30(60 \%)$ & \\
\hline \multirow[t]{4}{*}{ Social outcast by the society during this pandemic } & & Yes & No & \multirow[t]{4}{*}{0.15} \\
\hline & Group $\mathrm{P}+\mathrm{CG}$ & $93(30 \%)$ & $217(70 \%)$ & \\
\hline & Group P & $30(21.4 \%)$ & $110(78.6 \%)$ & \\
\hline & Group CG & $15(50 \%)$ & $15(50 \%)$ & \\
\hline \multirow[t]{4}{*}{ Financial loss because of lockdown } & & Yes & No & \multirow[t]{4}{*}{$0.02 *$} \\
\hline & Group P+CG & $186(60 \%)$ & $124(40 \%)$ & \\
\hline & Group P & $90(64.3 \%)$ & $50(35.7 \%)$ & \\
\hline & Group CG & $40(80 \%)$ & $10(20 \%)$ & \\
\hline \multirow{4}{*}{$\begin{array}{l}\text { Lack of support system for daily needs (groceries medical equipment etc.) because } \\
\text { of lack of support system }\end{array}$} & & Yes & No & \multirow[t]{4}{*}{0.09} \\
\hline & Group P + CG & $190(61.3 \%)$ & $120(38.7 \%)$ & \\
\hline & Group P & $100(71.4 \%)$ & $40(28.6 \%)$ & \\
\hline & Group CG & $30(60 \%)$ & $20(40 \%)$ & \\
\hline
\end{tabular}

Group P + CG $(N=310)$ : patients who came along with their caregivers

Group $\mathrm{P}(N=140)$ : patients alone

Group CG $(N=50)$ : caregivers alone

For comparison between three groups with each other, chi square test was used

$* P$ value of $<0.05$ was considered to be statistically significant

Table 5 Challenges faced at the level of the spiritual domain

\begin{tabular}{lllll}
\hline Challenges & Groups & Yes & No & P value \\
\hline Lack of spiritual and religious devo- & Group P+CG & $124(40 \%)$ & $186(60 \%)$ & 0.302 \\
tion during pandemic & Group P & $49(35 \%)$ & $91(65 \%)$ & \\
& Group CG & $15(30 \%)$ & $35(70 \%)$ & \\
Lack of spiritual clarity and hope & Groups & Yes & No & $\mathbf{0 . 0 0 0}$ \\
& Group P+CG & $155(50 \%)$ & $155(50 \%)$ & \\
& Group P & $75(53.6 \%)$ & $65(46.4 \%)$ & \\
Feeling of fatalism & Group CG & $10(20 \%)$ & $40(80 \%)$ & \\
& Groups & Yes & No & 0.394 \\
& Group P+CG & $31(10 \%)$ & $279(90 \%)$ & \\
& Group P & $20(14.3 \%)$ & $120(85.7 \%)$ & \\
& Group CG & $5(10 \%)$ & $45(90 \%)$ & \\
\hline
\end{tabular}

Group $\mathrm{P}+\mathrm{CG}(N=310)$ : patients who came along with their caregivers

Group $\mathrm{P}(N=140)$ : patients alone

Group CG $(N=50)$ : caregivers alone

For comparison between three groups with each other, chi square test was used

$* P$ value of $<0.05$ was considered to be statistically significant the level of burden faced by caregivers of cancer patients is much more than for caregivers caring for elderly patients [16]. They not only have to deal with their own responsibilities but also need to focus upon caring for their loved ones
[17]. Thus, it is equally important to address the challenges faced by caregivers as seen in this domain.

The spiritual domain is also one more aspect which is often overlooked but is extremely important for providing 
holistic care to the cancer patients [18]. Fifty percent patients and their caregivers reported that they faced lack of spiritual clarity and hope during the ongoing pandemic. But still majority took out time for religious and spiritual devotion and did not exhibit fatalism. Feeling of fatalism and lack of spiritual clarity were statistically significant when patients were alone as compared to when they had support of caregivers. Seema et al. in their study observed that signs of transformation in spiritual credence during the pandemic were evident in the form that majority could not attend their places of worship and were having lack of spiritual clarity. For coping with the stress and anxiety, majority resorted to path of prayer and chanting at home, with few having a belief in helping out others and participating in spiritual community sessions to overcome their problems in life [19].

\section{Limitations}

The study has been conducted at a single tertiary care center and thus would limit the generalizability of the study findings. Thus, there is a need to conduct a multi-centric study from different geographical locations to assess the challenges faced by cancer patients and their caregivers during a pandemic. This would help to formulate strategies to overcome the challenges and would be helpful in providing holistic care to cancer patients during future pandemics.

\section{Conclusion}

Major challenges faced by patients were in the physical and psychological domains, and those by caregivers were in the socioeconomic domain and handling physical symptoms of their patients. The COVID-19 pandemic exacerbated the previous challenges and symptoms and also led to the development of new challenges. It is imperative to recognize and be cognizant of the challenges faced by cancer patients and their caregivers. Now is the time that all the healthcare experts, governmental, and non-governmental organizations should come together, discuss the pertinent issues related to challenges faced by cancer patients and their caregivers, and formulate the strategies to mitigate those challenges so that the damage caused by this pandemic could be minimized and patients are provided with the holistic care. These strategies will hold in good stead for future pandemics also.

Author contribution All authors contributed to the study conception and design. Material preparation, data collection and analysis were performed by Seema Mishra and Raghav Gupta. The first draft of the manuscript was written by Raghav Gupta, and all authors commented on previous versions of the manuscript. All authors read and approved the final manuscript.
Data availability N/A

Code availability N/A

\section{Declarations}

Ethics approval Institute Ethics Committee of AIIMS Hospital, New Delhi, India (IEC-448/22/05.2020)

Consent to participate Informed consent was obtained from all individual participants included in the study.

Consent for publication Patients signed informed consent regarding publishing their data.

Conflict of interest The authors declare no competing interests.

\section{References}

1. W HO. WHO announces COVID-19 outbreak a pandemic (2020). www.euro.who.int/en/health-topics/health-emergencies/ coronavirus-covid-19/news/news/2020/3/who-announces-covid19-outbreak-a-pandemic. Accessed 2 July 2020

2. del Rio C, Malani PN (2020) COVID-19-new insights on a rapidly changing epidemic. JAMA. https://doi.org/10.1001/jama.2020. 3072

3. Zhou F, Yu T, Du R, Fan G, Liu Y, Liu Z et al (2020) Clinical course and risk factors for mortality of adult inpatients with COVID-19 in Wuhan, China: a retrospective cohort study. Lancet 395:1054-1062

4. Liang W, Guan W, Chen R, Wang W, Li J, Xu K et al (2020) Cancer patients in SARS-CoV-2 infection: a nationwide analysis in China. Lancet Oncol 21:335-337

5. Wu Z, McGoogan JM (2020) Characteristics of and important lessons from the coronavirus disease 2019 (COVID-19) outbreak in China: summary of a report of 72314 cases from the Chinese Center for Disease Control and Prevention. JAMA 323(13):12391242. https://doi.org/10.1001/jama.2020.2648

6. Wu JT, Leung K, Bushman M, Kishore N, Niehus R, de Salazar PM et al (2020) Estimating clinical severity of COVID-19 from the transmission dynamics in Wuhan. China Nat Med 26(4):506510. https://doi.org/10.1038/s41591-020-0822-7

7. Ingole SP, Kakde AU, Bonde PB (2016) A review on statistics of cancer in India. IOSR J Environ Sci 10:107-116

8. Pramesh CS, Badwe RA (2020) Cancer management in India during Covid-19. N Engl J Med 382:e61. https://doi.org/10.1056/ NEJMc2011595

9. Spicer J, Chamberlain C, Papa S (2020) Provision of cancer care during the COVID-19 pandemic. Nat Rev Clin Oncol 17:329-331

10. Brunetti O, Derakhshani A, Baradaran B, Galvano A, Russo A, Silvestris N (2020) COVID-19 infection in cancer patients: how can oncologists deal with these patients? Front Oncol 10:734

11. Gupta R, Sarma R, Mishra S, Bhatnagar S (2020) Rendezvous of cancer patients with logistic and socioeconomic challenges during COVID-19 pandemic: a case series. Indian J Palliat Care 26:S156-S159

12. Liu X, Liu F, Tong F et al (2020) Psychological reactions and interventions to help cancer patients cope during the COVID-19 pandemic in China. J Psychosoc Oncol Res Pract 2(3):e35

13. Coping with cancer: tools to help you live. CANCERcare Web site. http://media.cancercare.org/publications/original/3-ccc_coping.pdf. Accessed 4 Sep 2021 
14. Coping with the diagnosis of cancer. Stanford Medicine Web site. http://cancer.stanford.edu/information/coping/. Accessed 4 Sep 2021

15. Institute of Medicine (US) Committee on psychosocial services to cancer patients/families in a community setting (2008) Cancer care for the whole patient: meeting psychosocial health needs. Adler NE, Page AEK, editors. Washington (DC): National Academies Press (US)

16. Kim Y, Schulz R (2008) Family caregivers' strains: comparative analysis of cancer caregiving with dementia, diabetes, and frail elderly caregiving. J Aging Health 20(5):483-503

17. Beattie S, Lebel S (2011) The experience of caregivers of hematological cancer patients undergoing a hematopoietic stem cell transplant: a comprehensive literature review. Psycho-Oncol 20(11):1137-1150

18. Puchalski CM (2012) Spirituality in the cancer trajectory. Ann Oncol 23:49-55

19. Mishra S, Gupta R, Bharati SJ, Biswas S (2020) Transmutation of spiritual credence during COVID-19 era in cancer patients: a case series. Asian Pac J Cancer Care 5:129-132

Publisher's note Springer Nature remains neutral with regard to jurisdictional claims in published maps and institutional affiliations. 